perhaps empathise with more because they are played by adult actors.

The script was passed on to Soho Theatre Company soon after it was finished but this was around the time of the Bulger murder and police investigation. The Company decided to delay production until the case was over. This was not the move of a Theatre Company out to make money but that of a Company which takes art seriously and acts responsibly. It is perhaps not surprising therefore that the Tatler has claimed: "If there is going to be any theatre, apart from musicals, in 20 years time, Soho Theatre Company at the Cockpit (theatre) will probably have been its seed-bed." The play's current run ended in midJune but I am sure that we will see it again soon. Watch out for it.

Kwame McKenzie, Researcher, Institute of Psychiatry, London SE5 8AF

\title{
Sun, sea, sand and psychiatry
}

Neelam Slsodia and Corinne de Sousa see a message
for psychiatry in a film about Asian women

The denunciation of Gurinder Chadha and Meera Syal's film Bhaji on the Beach by selfstyled leaders of the Asian community on a recent local news programme ensured that we went to see it. Whereas Mira Nair's film Mississippi Masala was dismissed by certain elements of the Asian community in this country because it was set in America and depicted the lives of Ugandan Asians, Bhaji on the Beach is set in Birmingham. It is close to home, grittily authentic and hard to ignore. The film manages to raise many issues, several of which are of considerable relevance to psychiatry, particularly the mental health of women in an ethnic minority.

The title of the film refers to a picnic on the beach when a group of seemingly very different Asian women come together on a day trip to Blackpool. The outing is organised by Simi, an ardent feminist community worker who wears a leather jacket over a Punjabi suit. She runs the Saheli Asian Women's Centre as well as being involved in the Asian Women's refuge, currently home to Ginder and her young son Amrik. Ginder is wrestling with the dilemma of whether she should divorce her husband Ranjit because of violence within their 'love marriage'. She is initially ostracised by the older women in the group for bringing such shame on her family and is later joined 'in Coventry' by Hashida, a budding medical student, previously lauded for her academic achievements and good behaviour. but now found to be pregnant. The sin of premarital sex is compounded by the fact that the father of the baby is of African-Caribbean origin. Hashida and the two younger teenagers are each rebelling in some way. The three middle-aged women in the group have their own inner conflicts and perhaps reflect the teenagers as they might be in later life. Finally there is the spirited elderly woman who is the epitome of a traditional and, at times, more reactionary generation. The story line poignantly demonstrates many of the prejudices and problems faced by women such as these, not least from within their own society. However, as the day progresses the group dynamics change and they begin to understand each other, and no doubt themselves, a little better. Eventually they show acceptance, tolerance and support for one another. Within psychiatric services we also have to demonstrate tolerance and support for patients regardless of age, sex, race, religion and social class. This film carries a message for the planning and provision of these services.

One might expect that as time passes and Asian families become assimilated into British life, problems of race and culture will lessen. This is not necessarily so. In the film Rekha, visiting from Bombay, shows that city dwellers in India are often more broad-minded and tolerant in their outlook than Indians living abroad. The latter may adhere to the values they emigrated with, creating numerous problems for children raised between two cultures. They are trying not only to maintain links with their families and ethnic roots but also to gain acceptance from their adopted community. This can be particularly difficult for girls. In some Asian families male children are held in higher esteem than their female siblings, a legacy of a time when daughters were considered an economic burden because they generated no income but required large dowries upon marriage. While some things have changed for the better, a sense of inferiority among women may be established early in life. 
Young Asian women, like their peers, have to deal with issues such as pre-marital sex, teenage pregnancies and domestic violence. In addition they face racism, problems with inter-caste and inter-race relationships, and family ties strained by living in a culture perceived as alien by their parents. Educational opportunities for girls may be limited in an effort to reduce their exposure to unwanted influences.

Although many arranged marriages work very well, separation and divorce are becoming more common. However, marital problems and domestic violence often go unrecognised or ignored by the community. For those who have no employment outside the home, who have young children and no confidant in the form of a husband or close relative, the sense of isolation may be great. All these difficulties may contribute to the increase in psychiatric morbidity in Asian women as shown by studies of eating disorders, parasuicide and suicide.

A recent development within psychiatric services has been the creation of specific posts in multidisciplinary teams, to be filled by professionals who are themselves from minority racial groups. This is a positive step, but the assumption that all patients from ethnic minority groups will want to be seen by a worker from their own background may be erroneous. While it may be necessary and helpful when there is a language barrier, the fear that confidentiality may not be possible may prevent people in small close communities using the service. All mental health workers should have an awareness of relevant cultural backgrounds and the common difficulties of living in an adopted country.

However, one area where more ethnic minority workers may be needed is in the health care of the elderly. Typically, Asian families provided care at home for their elderly. In today's society more women seek employment and children may move away, so the extended family is fragmenting. It is no longer always possible to provide this care within the family and the rising number of elderly people may make increasing demands on medical services as a result. It is members of this group, experiencing language difficulties and believing in traditional values, who may appreciate a worker from a similar ethnic background.

Psychiatry has taken substantial steps towards addressing issues relevant to the mental health needs of ethnic minorities. However, increased efforts are required to reach places where people gather, for example, community centres and places of worship. This may help reduce the stigma of mental illness within the Asian community and increase service use.

*Neelam Sisodia, Registrar in Psychiatry; and Corinne de Sousa, Senior House Officer in Psychiatry, University Hospital, Nottingham NG7 $2 U H$

*Correspondence 